\title{
APLIKASI FORECASTING PENJUALAN MENGGUNAKAN METODE SEMI AVERAGE PADA TOKO RUMAH KITA MAKASSAR
}

\author{
Silce Patandean ${ }^{1}$, Askar $^{2}$, Mashud $^{3}$ \\ Sistem Informasi STMIK AKBA ${ }^{1}$, Manajemen, Universitas Patria Artha ${ }^{2}$, \\ Komputerisasi Akuntansi STMIK AKBA ${ }^{3}$ \\ Email: silcepatandean@gmail.com ${ }^{1}$, askartaliang22@gmail.com², mashud @akba.c.id ${ }^{3}$
}

\begin{abstract}
ABSTRAK
Toko Rumah Kita Makassar merupakan salah satu usaha yang menjalankan aktivitas sebagai tempat penjualan kebutuhan rumah tangga. Pengolahan laporan penjualan dilakukan menggunakan Microsoft Excel dan Microsoft Word sehingga pihak manajemen sulit dalam meramalkan barang-barang kebutuhan rumah tangga yang banyak diminati oleh konsumen berdasarkan data-data transaksi penjualan sebelumnya. Penelitian ini bertujuan untuk merancang dan mengimplementasikan Aplikasi Forecasting penjualan menggunakan metode semi average pada Toko Rumah Kita Makassar. Metode pengumpulan data yang digunakan yaitu metode Observasi, metode wawancara dan metode studi pustaka. Adapun desain model sistem pada penelitian ini dengan menggunakan UML (Unified Modelling Languange) mencakup use case diagram, activity diagram dan class diagram. Pengujian yang dilakukan dalam penelitian ini menggunakan pengujian black box terhadap segala fitur dan fungsi dalam sistem. Dari hasil perancangan dan implementasi Aplikasi Forecasting penjualan menggunakan metode semi average Pada Toko Rumah Kita Makassar menunjukkan bahwa aplikasi ini dapat berjalan dengan baik sehingga dapat menangani masalah pengambilan keputusan perencanaan penjualan agar sesuai target perusahaan.
\end{abstract}

\section{Kata Kunci: Aplikasi; Forecasting; Penjualan; Semi Average; Makassar}

\section{ABSTRCT}

Toko Rumah Kita Makassar is one of the businesses that runs activities as a place to sell household needs. Sales report processing is done using Microsoft Excel and Microsoft Word so that the management is difficult in predicting household goods that are in great demand by consumers based on previous sales transaction data. This study aims to design and implement Sales Forecasting Applications using the semi average method in Makassar Rumah Kita Stores. Data collection methods used are observation methods, interview methods and literature study methods. The design of the system model in this study using UML (Unified Modeling Language) includes use case diagrams, activity diagrams and class diagrams. Tests conducted in this study use black box testing of all features and functions in the system. From the results of the design and implementation of the Forecasting Application sales using the semi-average method At Toko Kita Kita Makassar shows that this application can run well so that it can handle the problem of making sales planning decisions to fit the company's target

Keywords: Application; Forecasting; Sales; Semi Average; Makassar 


\section{PENDAHULUAN}

Toko Rumah Kita Makassar merupakan salah satu usaha yang menjalankan aktivitas sebagai tempat penjualan kebutuhan rumah tangga. Penjualan merupakan faktor utama dalam menunjang kelangsungan hidup suatu perusahaan. Tingginya tingkat penjualan pada suatu perusahaan dapat dapat memberikan keuntungan bagi perusahaan atau toko tersebut. Oleh karena itu toko harus mampu dalam menentukan kebijakan-kebijakan yang berhubungan dengan aktivitas penjualan yang dilakukan oleh perusahaan.

Pengolahan laporan penjualan dilakukan menggunakan Microsoft Excel dan Microsoft Word sehingga pihak manajemen sulit dalam meramalkan barang-barang kebutuhan rumah tangga yang banyak diminati oleh konsumen berdasarkan data-data transaksi penjualan sebelumnya.

Untuk menangani masalah pengambilan keputusan perencanaan penjualan agar sesuai target perusahaan, maka diperlukan adanya Aplikasi Forecasting Penjualan Pada Toko Rumah Kita Makassar. Salah satu metode forecasting yang dapat digunakan dalam peramalan adalah metode semi average.

Metode trend semi average dapat digunakan untuk keperluan peramalan dengan membentuk suatu persamaan seperti analisis regresi. Metode semi average dapat digunakan dengan jumlah data genap ataupun ganjil. Persamaan trend yang diperoleh dengan menggunakan semi average selain dapat digunakan untuk mengetahui kecenderungan nilai suatu variabel dari waktu ke waktu, juga dapat digunakan untuk meramal nilai suatu variabel tersebut pada suatu waktu tertentu.

\section{LANDASAN TEORI}

\subsection{Aplikasi}

Menurut Hengky W Pramana (2012) Aplikasi adalah satu unit perangkat lunak yang dibuat untuK melayani kebutuhan akan beberapa aktivitas seperti sistem perniagaan, game, pelayanan masyarakat, periklanan, atau semua proses yang hampir dilakukan manusia. Biasanya dibandingkan dengan perangkat lunak sistem yang mengintegrasikan berbagai kemampuan komputer, tetapi tidak secara langsung menerapkan kemampuan tersebut untuk mengerjakan suatu tugas yang menguntungkan pengguna. Contoh utama perangkat lunak aplikasi adalah pengolah kata, lembar kerja, dan pemutar media. Kumpulan aplikasi komputer yang digabung menjadi suatu paket biasanya disebut paket atau suite aplikasi (application suite). Contohnya adalah Microsoft Office dan OpenOffice.org, yang menggabungkan suatu aplikasi pengolah kata, lembar kerja, serta beberapa aplikasi lainnya Aplikasi-aplikasi dalam suatu paket biasanya memiliki antarmuka pengguna yang memiliki kesamaan sehingga memudahkan pengguna untuk mempelajari dan menggunakan tiap aplikasi.

Umumnya aplikasi-aplikasi tersebut memiliki kemampuan untuk saling berinteraksi sehingga menguntungkan pemakai. Contohnya, suatu lembar kerja dapat dimasukkan dalam suatu dokumen pengolah kata walaupun dibuat pada aplikasi lembar kerja yang 
terpisah.Aplikasi adalah program siap pakai yang dapat digunakan untuk menjalankan printah-printah dari pengguna aplikasi tersebut dengan tujuan mendapatkan hasil yang lebih akurat sesuai dengan tujuan pembuatan aplikasi tersebut, aplikasi mempunyai arti yaitu pemecahan masalah yang menggunakan salah satu tehnik pemrosesan data aplikasi yang biasanya berpacu pada sebuah komputansi yang diinginkan atau diharapkan maupun pemrosesan data yang diharapkan Berdasarkan jenisnya

\subsection{Forcasting}

Forecasting adalah memprediksikan dari beberapa peristiwa atau banyak peristiwa yang akan datang. Menurut Neils Bohryang dikutipoleh Montogmery, Jennings, dan Kulhaci (2015), membuat prediksi yang bagus tidak selalu mudah. Forecasting merupakan permasalahan penting yang dapat mencakup banyak bidang termasuk bisnis dan industri, pemerintahan, ekonomi, ilmu lingkungan, medis, ilmu sosial, politik, dan keuangan.

\subsection{Forcasting Penjualan}

Pengertian peramalan penjualan menurut Nafarin (2015), "Ramalan Jualan (sales forecasting) merupakan proses aktivitas memperkirakan produk yang akan dijual di masa mendatang dalam keadaan tertentu dan dibuat berdasarkan data yang pernah terjadi dan/atau mungkin terjadi." Menurut Rahayu dan Rachman (2013:31), "taksiran penjualan (sales forecasting) adalah suatu teknik proyeksi tentang tingkat permintaan konsumen potensial pada suatu periode tertentu dengan menggunakan berbagai asumsi tertentu, atau suatu cara untuk mengukur atau menaksir kondisi bisnis di masa yang akan datang."
Menurut Adisaputro dan Asri (1983), menyatakan bahwa "Forecast Penjualan adalah proyek teknis daripada permintaan langganan potensial untuk suatu waktu tertentu dengan berbagai asumsi." Dan menurut Menurut Yamit dikutip oleh Agustinawati Purba (2015) peramalan disebut juga perkiraan atau forecasting, merupakan alat bantu yang efektif dan efesien khususnya didalam bidang ekonomi. Dari berbagai pendapat tersebut maka dapat disimpulkan bahwa peramalan penjualan adalah teknik memperkirakan tingkat permintaan konsumen terhadap produk yang akan dijual dengan cara mengukur atau menaksir kondisi bisnis di masa yang akan datang berdasarkan data yang pernah terjadi.

Adapun tujuan dari peramalan penjualan menurut Dharmanegara (2010) "adalah untuk mengurangi risiko dalam pengambilan keputusan, untuk perencanaan keuangan dan manajemen strategi puncak." Manajer pemasaran menggunakan ramalan penjualan untuk menentukan alokasi optimal tenaga penjualan, menyusun tujuan penjualan dan merencanakan promosi dan iklan.

\subsection{Semi Average}

Metode trend setengah rata-rata menentukan bahwa untuk mengetahui fungsi $Y=a+b x$, semua data historis dibagi menjadi dua kelompok dengan jumlah anggota masing-masing sama (Andi Supangat, 2013).

1) Metode Setengah Rata-rata dengan data historis dalam jumlah genap.

2) Metode Setengah Rata-rata dengan data historis dalam jumlah ganjil

Persamaan trend yang diperoleh dengan menggunakan metode ini, selain dapat digunakan untuk mengetahui kecenderungan nilai suatu variabel dari waktu ke waktu, juga dapat digunakan 
untuk meramal nilai suatu variabel tersebut pada suatu waktu tertentu. Persamaannya adalah sebagai berikut:

$$
\mathrm{b}=\mathrm{Y} 2-\mathrm{Y} 1 / \mathrm{n}
$$

Keterangan :

b : perubahan nilai variabel setiap tahun.

Y1 : rata-rata kelompok pertama

Y2 : rata-rata kelompok kedua

$\mathrm{n}$ : periode tahun antara tahun $\mathrm{A}$

\section{METODE PENELITIAN}

\subsection{Metode Pengumpulan Data}

Ada tiga metode pengumpulan data yang gunakan yaitu:

1) Metode Observasi

Dalam hal ini dilakukan adalah melihat serta mempelajari secara konflik yang ada dilapangan yang erat kaitannya dengan objek yang diteliti.

2) Metode Wawancara

Dalam metode ini kegiatan yang dilaksanakan adalah melakukan diskusi serta tanya jawab dengan sumber yang dianggap memiliki pengetahuan yang lebih dalam dari permasalahan penelitian.

3) Metode Studi Pustaka

Metode yang dilakukan adalah dengan cara mencari bahan yang mendukung dalam pendefenisian permasalahan melalui buku-buku, internet, yang erat kaitannya dengan objek permasalahan.

\subsection{Metode Perancangan}

Adapun pemodelan sistem menggunakan Unified Modeling Language (UML).

1) Use Case

Use Case adalah sebuah kegiatan atau juga interaksi yang saling berkesinambungan antara aktor dan juga sistem. Atau dengan kata lain teknik secara umum digunakan, guna mengembangkan software / sistem informasi, guna memperoleh kebutuhan fungsional dari sistem yang ada. Gambar 1 merupakan gambar use case diagram pada Aplikasi Forecasting Penjualan Menggunakan Metode Semi Average Pada Toko Rumah Kita Makassar.

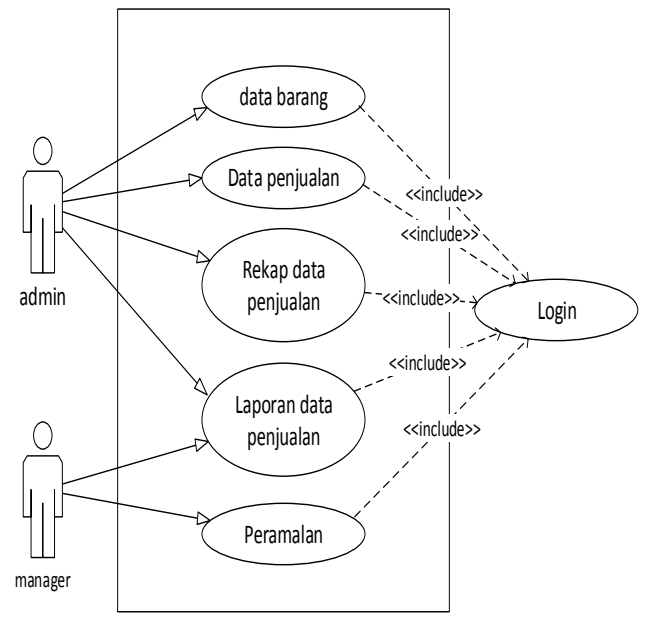

Gambar 1. Use Case Diagram

\section{2) Activity Diagram}

Activity Diagram merupakan alur kerja (workflow) atau kegiatan (aktivitas) dari sebuah sistem atau menu yang ada pada perangkat lunak. Activity Diagram juga digunakan untuk mendefinisikan urutan atau pengelompokan tampilan dari sistem/user interface dimana setiap aktivitas dianggap memiliki sebuah rancangan antar muka tampilan serta rancang menu yang ditampilkan pada perangakat lunak. Gambar 2 dan gambar 3 merupakan gambar diagram activity pada Aplikasi Forecasting Penjualan Menggunakan Metode Semi Average Pada Toko Rumah Kita Makassar.

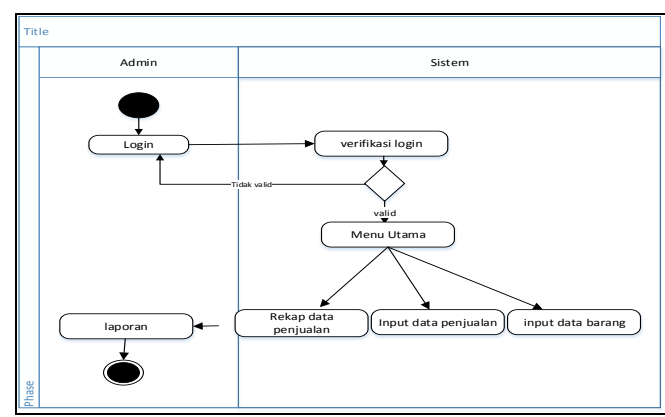

Gambar 2. Activity Diagram Admin 


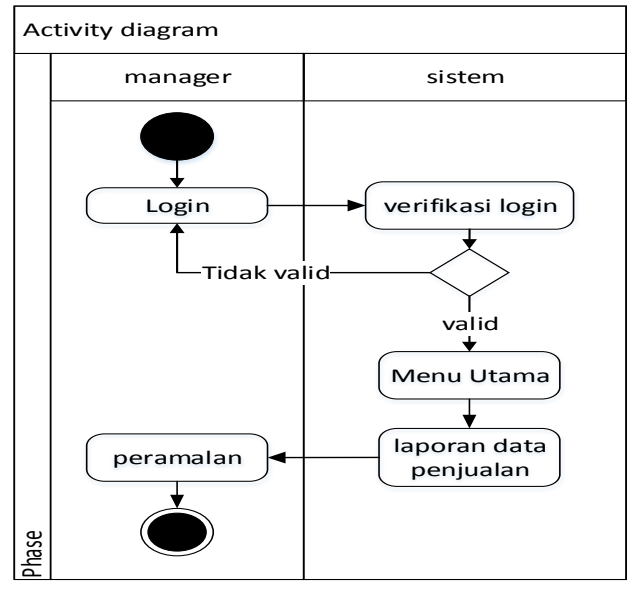

Gambar 3. Activity Diagram Manager

3) Class Diagram

Gambar 4 merupakan gambar class diagram pada Aplikasi Forecasting Penjualan Menggunakan Metode Semi Average Pada Toko Rumah Kita Makassar.

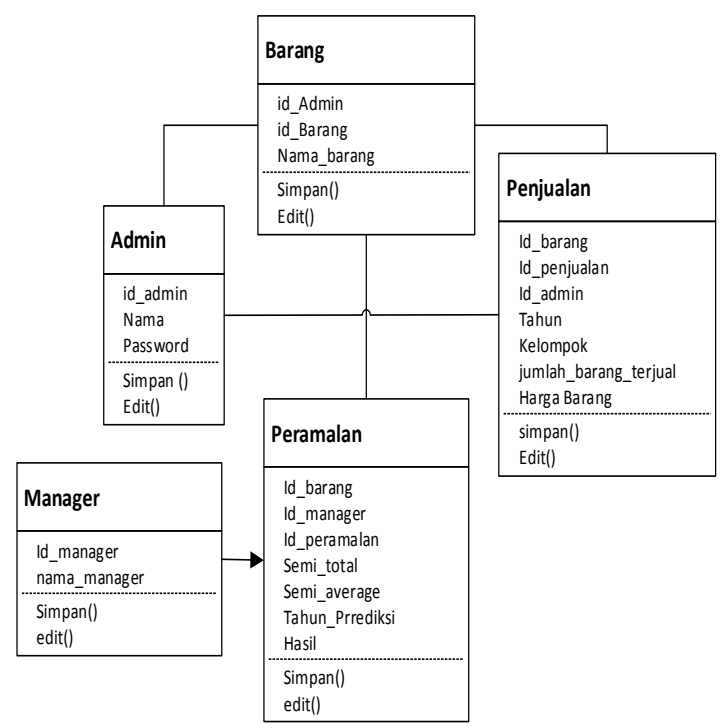

Gambar 4. Class Diagram

\section{HASIL DAN PEMBAHASAN}

Hasil implementasi penelitian berdasarkan analisis yang telah dilakukan yang mencakup implementasi sistem serta tahap-tahap pengujian dari sistem yang telah dibuat untuk mengetahui tingkat keberhasilan dari sistem tersebut

\subsection{Hasil Pengujian Sistem}

Pengujian yang dilakukan meliputi pengujian black box terhadap segala fitur dan fungsi dalam sistem yang ditunjukan sebagai berikut :

1) Pengujian Login

Tabel 1. Hasil Pengujian Form Login

\begin{tabular}{|l|l|c|}
\hline \multicolumn{1}{|c|}{ Skenario Pengujian } & Hasil yang diharapkan & Hasil \\
\hline $\begin{array}{l}\text { Mengisi username dan } \\
\text { password dengan data } \\
\text { yang tidak valid atau } \\
\text { salah }\end{array}$ & $\begin{array}{l}\text { sistem menolak akses } \\
\text { dengan informasi "login } \\
\text { gagal username dan } \\
\text { password salah" }\end{array}$ & Diterima \\
\hline $\begin{array}{l}\text { Mengisi username dan } \\
\text { password dengan data } \\
\text { yang valid atau benar }\end{array}$ & $\begin{array}{l}\text { Sistem menampilkan } \\
\text { halaman utama aplikasi }\end{array}$ & Diterima \\
\hline "Klik Login" & $\begin{array}{l}\text { Admin akan masuk di } \\
\text { menu utama (home). }\end{array}$ & Diterima \\
\hline
\end{tabular}

Pada tabel 1. Dapat dilihat bahwa hasil pengujian form login hasil yang diharapkan semuanya dapat diterima sesuai skenario pengujian.

2) Pengujian Form Peramalan

Tabel 2. Hasil Pengujian Form Peramalan

\begin{tabular}{|l|l|c|}
\hline Skenario pengujian & \multicolumn{1}{|c|}{ Hasil Yang Diharapkan } & Hasil \\
\hline $\begin{array}{l}\text { "Klik menu } \\
\text { Peramalan" }\end{array}$ & $\begin{array}{l}\text { Sistem akan menampilkan } \\
\text { sub menu Peramalan }\end{array}$ & Diterima \\
\hline "Klik pilih" & $\begin{array}{l}\text { Sistem akan menampilkan } \\
\text { barang yang akan di ramal }\end{array}$ & Diterima \\
\hline "Klik tahun" & $\begin{array}{l}\text { Sistem akan menampilkan } \\
\text { tahun berapa yang akan } \\
\text { diramal }\end{array}$ & Diterima \\
\hline $\begin{array}{l}\text { "Klik pilih dan } \\
\text { prediksi" }\end{array}$ & $\begin{array}{l}\text { Sistem akan menampilkan } \\
\text { hasil dari peramlan }\end{array}$ & Diterima \\
\hline
\end{tabular}

Pada tabel 2. Dapat dilihat bahwa pengujian halaman peramalan hasil yang diharapkan semuanya dapat diterima sesuai skenario pengujian. 


\subsection{Implementasi}

Implementasi sistem merupakan tahapan mengenai penjelasan dari penerapan sistem yang telah dirancang. Data yang digunakan pada penelitian ini data penjualan barang pada Toko Kita Makassar dengan menggunakan metode tahunan untuk menghitung forecasting. Sebagai contoh untuk penjualan "Kompor gas" dengan penjualan setiap tahunnya seperti pada tabel 3. Jika ingin meramalkan penjualan pada tahun 2018 dengan menggunakan data selama 6 tahun sebelumnya yaitu tahun 2012, 2013, 2014, 2015, 2016 dan 2017.

Tabel 3. Data Penjualan Kompor Gas

\begin{tabular}{|c|c|}
\hline Tahun & Data Penjualan \\
\hline 2012 & 900 \\
\hline 2013 & 1.000 \\
\hline 2014 & 950 \\
\hline 2015 & 1.050 \\
\hline 2016 & 1.100 \\
\hline 2017 & 1.000 \\
\hline 2018 & 1.200 \\
\hline Maka perhitungannya sebagai
\end{tabular}

berikut :

Menentukan nilai $\mathrm{b}$ dilakukan dengan cara membagi selisih antara nilai semi average kelompok 2 dan 1 dengan jumlah data dalam kelompok. Berikut persamaannya :

$$
\mathrm{b}=\frac{\mathrm{Y}_{2}-\mathrm{Y}_{1}}{\mathrm{n}}
$$

$\mathrm{Y}_{1}=$ nilai semi average kelompok 1

$\mathrm{Y}_{2}=$ nilai semi average kelompok 2

$\mathrm{n} \quad=$ jumlah tiap kelompok

$$
\mathrm{b}=\frac{1050-950}{3}=33,33333333
$$

Dari persamaan tersebut diatas, di tentukanlah nilai a dan b sehingga persamaan untuk peramalan dengan cara sebagai berikut.

$$
\mathrm{Y}=\mathrm{a}+\mathrm{b}(\mathrm{x})
$$

dimana nilai $a=$ nilai semi average kelompok 1 , dan $\mathrm{x}=$ periode (tahun 1 )

$$
\begin{aligned}
& \mathrm{Y}^{\prime}{ }_{1}=950+33(1)=983 \\
& \mathrm{Y}^{\prime}{ }_{2}=950+33(2)=1.016 \\
& \mathrm{Y}^{\prime}{ }_{3}=950+33(3)=1.049 \\
& \mathrm{Y}^{\prime}{ }_{4}=950+33(4)=1.082 \\
& \mathrm{Y}^{\prime}{ }_{5}=950+33(5)=1.115 \\
& \mathrm{Y}^{\prime}{ }_{6}=950+33(6)=1.148 \\
& \mathrm{Y}^{\prime}{ }_{7}=950+33(7)=1.183
\end{aligned}
$$

Dari hasil perhitungan didapatkan bahwa peramalan jumlah penjualan untuk tahun 2018 adalah sebesar 1.1183 unit.

\subsection{Tampilan Apilkasi}

Aplikasi Forecasting Penjualan Menggunakan Metode Semi Average Pada Toko Rumah Kita Makassar dapat mempermudah pihak Manager dalam meramalkan penjualan tiap tahun. Berikut tampilan aplikasi.

1) Halaman Login

Form login berfungsi untuk melakukan verifikasi data user yang memiliki peran dalam menggunakan aplikasi, seperti pada gambar 5 berikut.

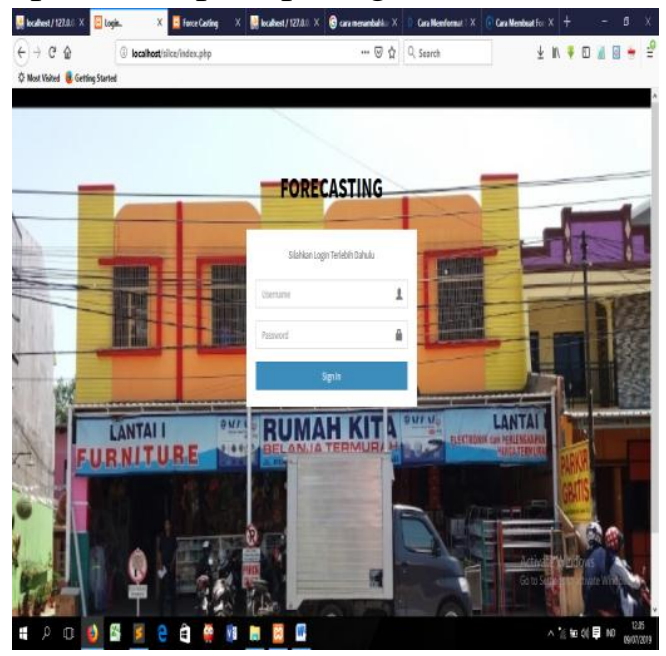

Gambar 5. Halaman Login 
2) Halaman Data Barang

Tampilan halaman data barang adalah tampilan dimana admin dapat memproses penambahan, pengeditan dan penghapusan data barang, seperti pada gambar 6 berikut.

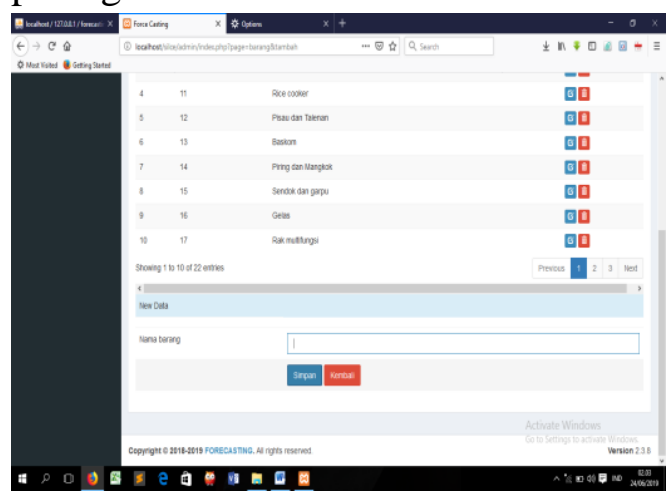

Gambar 6. Halaman Data Barang

3) Halaman Data Penjualan

Tampilan halaman data penjualan adalah tampilan dimana admin dapat menambah, menghapus dan mengedit data penjualan, seperti pada gambar 7 berikut.

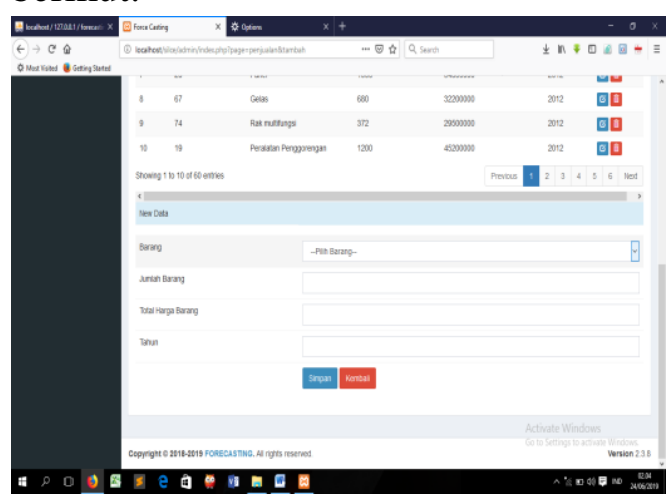

Gambar 7. Halaman Data Penjualan

4) Halam Peramalan

Pada laman ini sistem akan menampilkan Peramalan yang akan di kelolah oleh Manager, pada laman ini menunjukkan hasil peramalan sesuai jenis barang dan tahun peramalan dipilih. Sebagai contoh pada gambar 8 berikut memilih produk kompor gas dan tahun 2018 untuk peramalan.

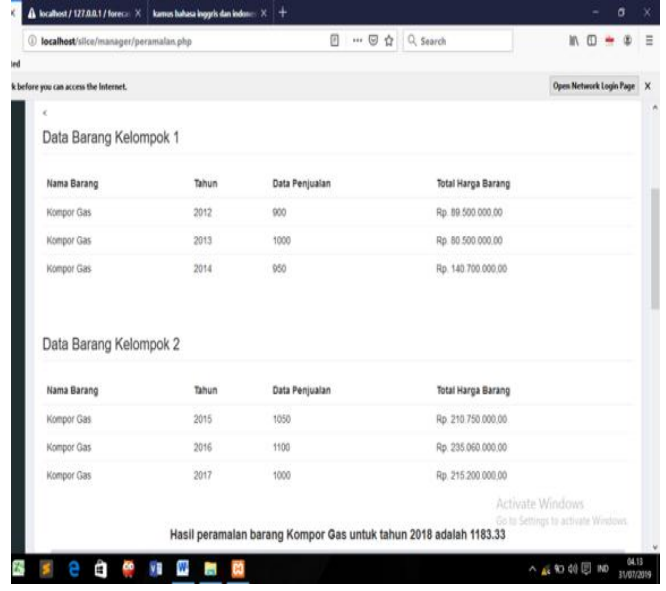

Gambar 8. Halaman Peramalan

5) Grafik Penjualan

Pada laman ini sistem akan menampilkan grafik penjualan barang pertahun, seperti pada gambar 8 berikut.

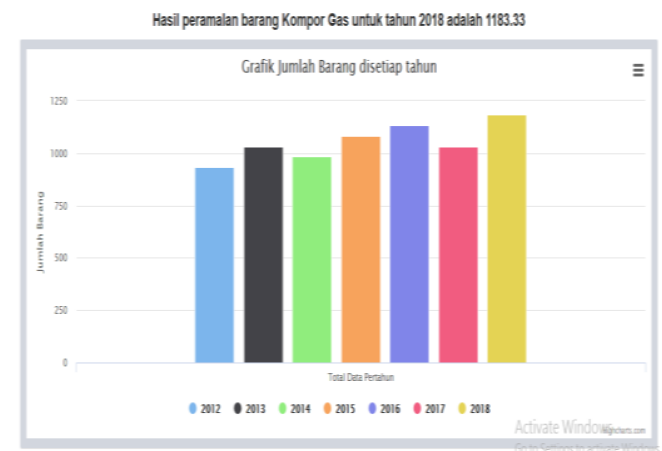

Gambar 9. Grafik Penjualan

\subsection{Pembahasan}

Dari hasil pengujian black box pada tabel 1 dan tabel 2 dapat dilihat bahwa perancangan aplikasi ini dapat berjalan dengan baik karena semua hasil pengujian diterima. Dan dari hasil contoh perhitungan peramalan barang jenis "Kompor gas" pada tahun 2018 di dapatkan sebesar 1.183 unit sama dengan dengan hasil peramalan di gambar 8. Jika dibandingkan dengan data penjualan "Kompor gas" pada tabel 3 sebesar 1.200 Unit, maka keakuratan peramalan sebesar $98,5 \%$. 


\section{SIMPULAN DAN SARAN}

\subsection{Simpulan}

Dari hasil perancangan dan implementasi aplikasi forecasting penjualan menggunakan metode semi average pada Toko Rumah Kita Makassar ini menunjukkan bahwa aplikasi ini dapat berjalan dengan baik sehingga dapat menangani masalah pengambilan keputusan perencanaan penjualan agar sesuai target perusahaan.

\subsection{Saran}

Saran yang diharapkan yaitu adanya pengembangan aplikasi yang dapat terintegrasi dengan sistem lain yang dapat mendukung kegiatan perusahaan dan dapat mengembangkan dengan menggunakan metode lain.

\section{DAFTAR PUSTAKA}

Adisaputro, Gunawan dan Asri,Marwan. (2000). Anggaran Perusahaan. Yogyakarta. BPFI.

Agustinawati Purba. Desember (2015). Perancangan Aplikasi Peramalan Jumlah Calon Mahasiswa Baru Yang Mendaftar Menggunakan Metode Single Exponential Smothing. Jurnal Riset Komputer (JURIKOM), Vol. 2 No. 6, Desember 2015.

Alfian Nurlifa, Sri Kusumadewi. (2017). Sistem Peramalan Jumlah Penjualan Menggunakan Metode Moving Average Pada Rumah Jilbab Zaky. Jurnal INOVTEK POLBENG - seri Informatika, Vol. 2, No. 1, Juni 2017.

Dharmanegara, Ida Bagus Agung. (2010). Penganggaran Perusahaan: Teori dan Aplikasi. Yogyakarta: Graha Ilmu.

Hengky W. Pramana, (2012). Aplikasi Inventory Berbasis Access 2003. Jakarta. PT. Elex Media Komputindo,
Montgomery, C. Douglas, Jennings, L. Cheryl, and M. Kulahci 2015, "Introduction to Time Series Analysis and Forecasting Second Edition," NewJersey: John Wiley \& Sons. Inc,.

Nafarin, M. 2015. Penganggaran Perusahaan. Edisi tiga. Jakarta: Salemba Empat

Rahayu, Sri dan Andry Arifian Rachman. (2013). Penyusunan Anggaran Perusahaan. Yogyakarta: Graha Ilmu 